\title{
DECIPHERING THE IMPRESSION OF ADVERTISING THROUGH CHILD ART
}

\author{
Setu Sharma ${ }^{1} \square$ (D), Dr. Ujjvala M. Tiwari ${ }^{2} \square$ (iD) \\ Research Scholar, Department of Visual Arts, IIS (Deemed to be University), Jaipur, Rajasthan, India. \\ ${ }^{2}$ Associate Professor, Department of Visual Arts, IIS (Deemed to be University), Jaipur, Rajasthan, India.
}
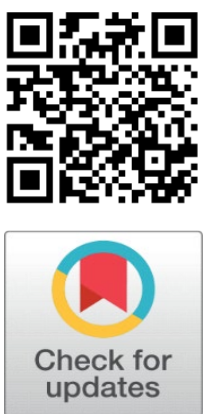

Received 14 October 2021

Accepted 15 November 2021

Published 14 December 2021

\section{CorrespondingAuthor}

Setu Sharma, setusharma@outlook.com DOI

\subsection{1/shodhkosh.v2.i2.2021.55}

Funding: This research received no specific grant from any funding agency in the public, commercial, or not-for-profit sectors.

Copyright: (C) 2021 The Author(s). This is an open access article distributed under the terms of the Creative Commons Attribution License, which permits unrestricted use, distribution, and reproduction in any medium, provided the original author and source are credited.

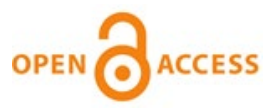

\section{ABSTRACT}

The easier and expressive forms of child art are scribbling and drawing. Drawing made by children, mirror their personality and understanding of their cultural environment. It also helps them in expressing their feelings, emotions, preferences, likes, dislikes, fears, joy, and so on. Sometimes the art and drawing unveil information which they do not express through verbal or written communication.

In this digital era, children get exposed to a lot of advertisements through various media. Some of these advertisements have a long-lasting impact on them. The advertised message or some visuals of the advertisement may remain in their conscious or subconscious memory. Advertisers also make efforts to ensure that their message retains in the memory of young prospects. Because when these prospects make the buying decision, the probability of it being in the brand's favour increases. Advertising has a huge influence on the young, tender, and impressionable minds of the children. It reflects in their action and personality. In this research study, I tried to understand the impact of advertisements on children through deciphering their drawings. The children under this research study are from the age group of 8 to 12 years. Their drawings were studied to understand the impression of advertisements on them. The result shows that the advertisements have a noticeable impact on the children which is visible in their drawings.

Keywords: Children, Child Art, Drawing, Advertising, Brand

\section{INTRODUCTION}

Children learn a lot through observing and imitating others in their surroundings. Once they develop neat pincer grasp somewhere around the age of 12 to 15 months, they start scribbling by imitating others. During this stage, their scribbling doesn't have any meaning associated to it. However slowly these scribbles start taking shape and meaning. During the middle childhood when children have already developed their fine motor skills, their drawings become more refined, and they also start expressing themselves through their drawings. They express their thoughts, feelings, and emotions through their drawings Quaglia et al. (2015). They usually include the objects and information in their drawings which influenced their thoughts.

Due to the exponential growth of media and cutthroat competition children are bombarded with the advertisements. The daily exposure to advertisements raised drastically, children get exposed to many advertisements and brands on routine basis. They also get exposed to the advertisements and brands of the products which they use in their routine life. Their colour scheme, packaging, 
advertisements, and brand identity, etc., create an impact on the young minds which usually goes unnoticeable. The understanding of advertising messages and brand value starts to develop in children during their middle childhood, around the age of 7 to 13 years. During this age, the role and importance of peers also increases. The preferences of the peers influence their decisions. At this age child starts understanding the concept of social importance. At times, they buy things just to impress their peers or to gain social recognition among their group.

Growth of media and Internet gave birth to many creative and innovative ways of advertising. Earlier, advertising was one-way communication but, due to interactive media it has become two-way communication. Advertisers try to involve the prospects and consumers in a dialogue to extract information from them, as it helps them to make their products or services better. They also target children through interactive techniques. Young children are not able to comprehend these tactics and they fall prey to them. Advertisers collect information from children to enhance their products which leads to better experience, as it is based on their direct feedback. Moreover, it remains in their long-term memory which increases the probability of them being brand loyal in future.

In this research, I tried to find out the impression of advertisements on the young impressionable minds through their drawings. The information revealed through their drawings shows a noticeable impression of advertisement which usually goes unnoticed.

\section{UNDERSTANDING CHILDREN'S DRAWING}

Child art is one of the forms or expressions through which children communicate. It is universal in nature because this form of art can be seen all over the world. Moreover, they look similar to each other. Children go through various stages of art development. The age of the child is directly related to the variation in their art styles and development. As they grow in age their artworks become more refined. Although age is most important component in the development of child art, but there are various other components which may influence the artistic development of a child. There are various models to describe and explain the stages of development in child art. However, if we look at the development of child art in context to visual appearance then the initial stage starts from scribbling, and finally develops into the realistic representation of the world. During the initial stages, the drawing is more like free hand movement without proper control and coordination. Therefore, the forms look like scribbles or squiggles. It is because they feel pleasure in freely moving a pen, pencil, or crayons to create marks on a surface. This is the beginning of their art journey.

Once the child starts to realize that there is a link between the movement of their hand and the impression or marks created on the paper, they start to control their hand movements. They try to create patterns through moving hands in a controlled manner, resulting in basic geometric shapes through combining lines. Once they start creating shapes, they further try to develop forms by combining these shapes. They also associate meaning with them. Once the child realizes that the shapes drawn by them may have certain meaning assigned to it then they start using these shapes to represent their thoughts and ideas Golomb (2004). However, sometimes the visual output may not appear to relate to the intended object, or the meaning they try to represent.

During the age of 3-4 years, children start drawing human figures in which they draw a circle for depicting head and then join lines to it for creating body, arms, and 
legs. These human figures in symbolic form are known as tadpole figures Willats (2005). The visual difference in various tadpole figures drawn by a child is not too much but the child may have different association with different figures. For him one might be his/her brother or the other might be his/her mother.

During 4-5 years of age, children start exploring the tadpole figures more. They draw the body parts which they think are important and may skip the remaining details. They draw what they think is important and have some role to play in their drawing. There drawings express what they think and feel about the objects, and humans in their surroundings, instead of what they exactly look like.

In the pre-school or early school age, children do not understand the concept of space. They do not place the object as they are spatially placed in their surroundings. The objects usually float in their drawing Arnheim (2004). There's no concept of baseline, foreground, or background instead they consider the whole sheet or drawing space as their space to draw and place the objects.

At the age of 5 to 7 years, children have already developed a symbolic representation of the things around them. These symbols are based on their understanding or concept about that thing instead of its visual appearance. When they develop a symbolic representation of a particular thing or a person, they repeat the same symbolic form to represent them in all their drawings. Because these symbolic forms are based on the concept in their mind. They only change or modify it when they have some related experience or a reason to do so. They also develop the concept of baseline and start organizing the objects accordingly, so that the objects do not seem to be float in their drawings. Initially, they consider the bottom edge of the page as their baseline but gradually they develop this understanding that any line which cut across the page horizontally may serve as a baseline, where the objects can be placed. They also start using the space below baseline as foreground and above baseline as background. At the same time, they develop the concept of $\mathrm{x}$ ray drawing. They use x-ray drawing when they feel that the inside details are more important than the outside one Hurwitz and Day (2007) for example: Figure 1.

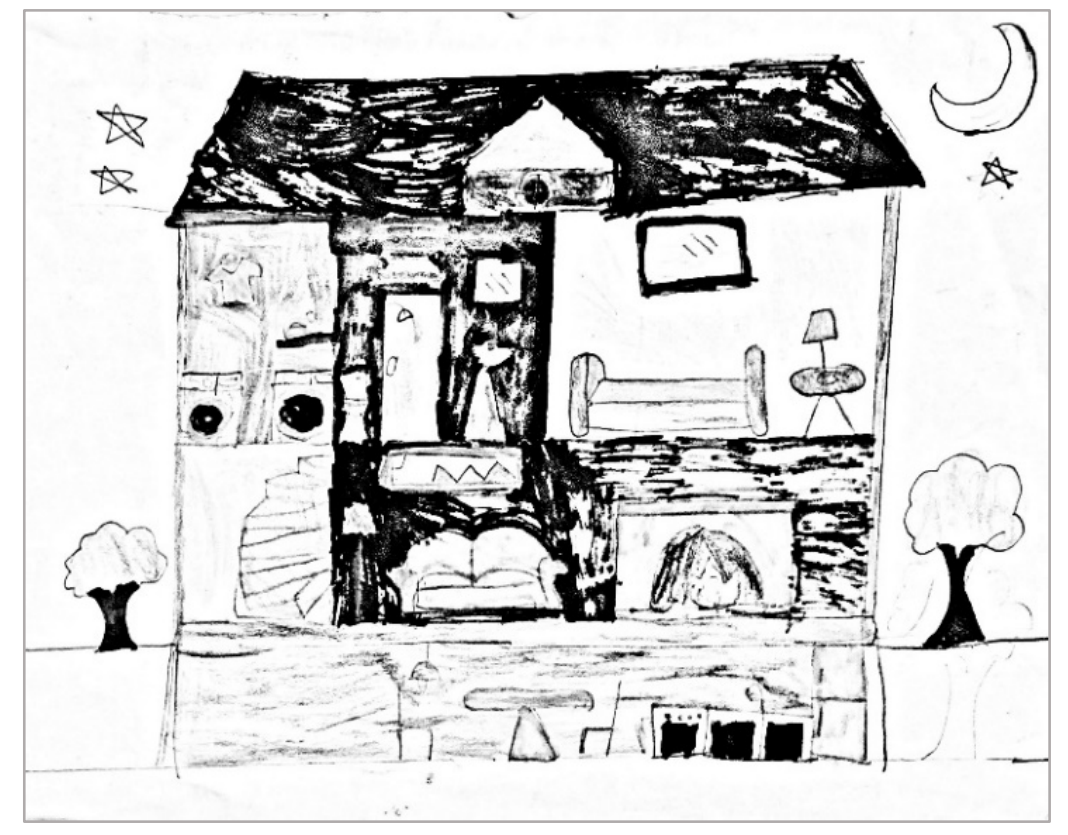

Figure 1 X-ray drawing of a house. 
Children aged between 8 to 10 years become more visually aware of the details. They try to incorporate these details into their drawings search as eyelashes, fingernails, nostrils, knuckles, and so on. They try to create realistic drawings and when they lack in doing the same, they get disappointed, and hesitate to draw further. They also try to copy the images or illustrations to achieve more realistic outcome. During the age of 8 to 12 years, children start understanding the concept of two-dimensions and three-dimensions. A huge influence of the culture is also noticeable in children's drawings. They draw what they see around them, whether physically or virtually. Media also influence their drawings because they get exposed to many visual forms through various media such as print, online, outdoor, television, and so forth. During their middle childhood, they start copying their favourite cartoon characters and use them in their drawings to depict themselves. Some children create their own character which depicts their fascination about a particular thing or helps them in depicting their fantasy world.

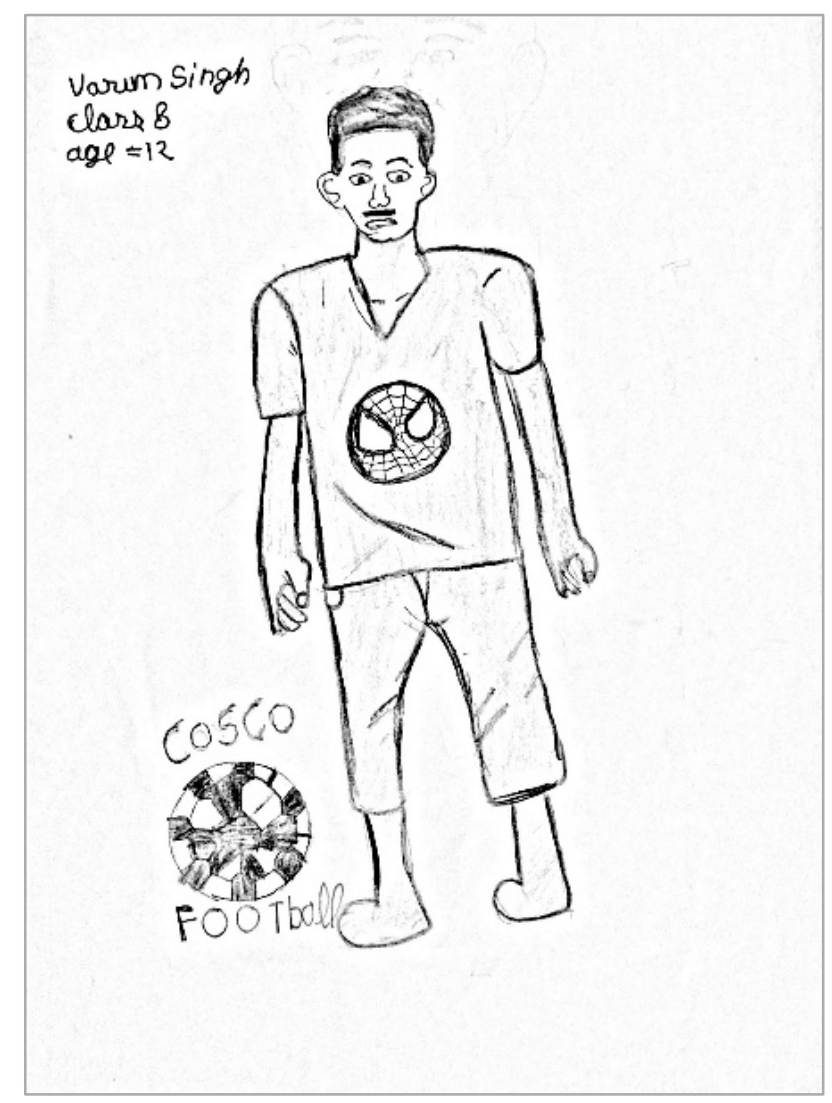

Figure 2

\section{IMPRESSION OF ADVERTISING}

Advertising is used as a medium of communication where the advertiser and producer communicates intended message to the prospects and consumers Sharma and Gupta (2015). Reach of the advertisers to prospects and consumers have increased drastically due to the explosion of media. Now advertisers have access to various creative and innovative media forms. It helps them in making their advertisements more creative and interesting. This increased reach of media made it easier and more flexible for the advertisers to reach children in their personal 
time. They target them either as consumers or persuaders, to influence their parents' buying decisions. The influence of advertisement on children varies based on their age. In the early childhood, children do not understand the difference between advertising and communication. Whereas, during the middle childhood they start understanding that the purpose of advertising is to sell Blades et al. (2014). However, they find Ads interesting, but they are not able to differentiate between the reality and the advertisement. They believe all the things shown in the advertisement are true and real. During the age of adolescence, they start understanding the purpose and the intention of the advertisements. They also start acting and behaving like consumers.

Apart from media explosion, the other factor which contributes to the increased advertising for children is the private and easy accessibility of media. Especially, through television and Internet. Most of the children have television in their rooms even some of them have their personal smartphone, tablet, laptop, or computer. In this scenario, the parents cannot monitor or supervise them all the time. This is a matter of concern. Media like Internet, which is interactive in nature, raises concern regarding advertisements and advertising practices. Marketers and advertisers try to target children to conduct market research and to seek information through creative surveys and questionnaires. Which, they later use it to enhance the consumer experience. They also use it to customize the products based on the feedback received from the children, as they are their intended target audience. It further helps them in adding more value, deriving more consumer satisfaction which leads to increased brand preference.

The cognitive development of a child also plays an important role in how he/she perceives the advertisement and its message. Children below the age of five years find difficulty in differentiating the television programmes and advertisements whereas children below the age of eight years face difficulty in understanding the persuasive nature of advertisements. They are not able to comprehend the biased nature of the advertisement. They believe that the characters or celebrities shown in the advertisement uses the advertised products in their real life Saraf (2013). These factors contribute to create an impression of advertising on children.

\section{METHODOLOGY}

Drawing is an activity which is full of fun and enjoyment for children. They use drawings to express their feelings, emotions, and perception of the world around them. Sometimes, when they are short of words, they try to express themselves through their drawings. Children drawing also serves as a communication medium between the creator and viewer. Children communicate and express their thoughts which they have in their conscious or subconscious mind through these drawings Anning and Ring (2004). At the same time, viewers may understand and decipher these young artists personalities through their drawings. Forms, colours, shapes, composition, and various other components in their drawing talks about their personality. These components of visual art composition or graphic elements are somewhat common. This shows an interrelation between child art and advertisements in visual or audio-visual formats.

Various visual components play an important role in making the advertisements effective. Sometime the slogans or jingles are so catchy, that they create a long-lasting impact on the consumers or prospects. Whereas, if we talk about the visual elements of advertisements, the amalgamation of text and graphics 
helps in generating feelings, emotions, and actions Eynullaeva and WoodwardSmith (2012).

Graphic elements play an important role in both child art and advertisements. Therefore, I have used them as a tool to decipher the impression of advertising on children which might not be communicated through words but is visible in their drawings. Sometimes, drawing or child art also helps in revealing the hidden thoughts and experiences in the child's mind, which they usually do not communicate. These thoughts and experiences remain unexpressed because they don't consider them important or worthy to share. In this research, I tried to extract these uncommunicated thoughts and expressions in the mind of children in context to advertising. For this, I used children's drawings, a form of child art as a tool of expression. In this research, 30 children of 8-12 years of age were involved. The agewise distribution of children is shown in Figure 3:

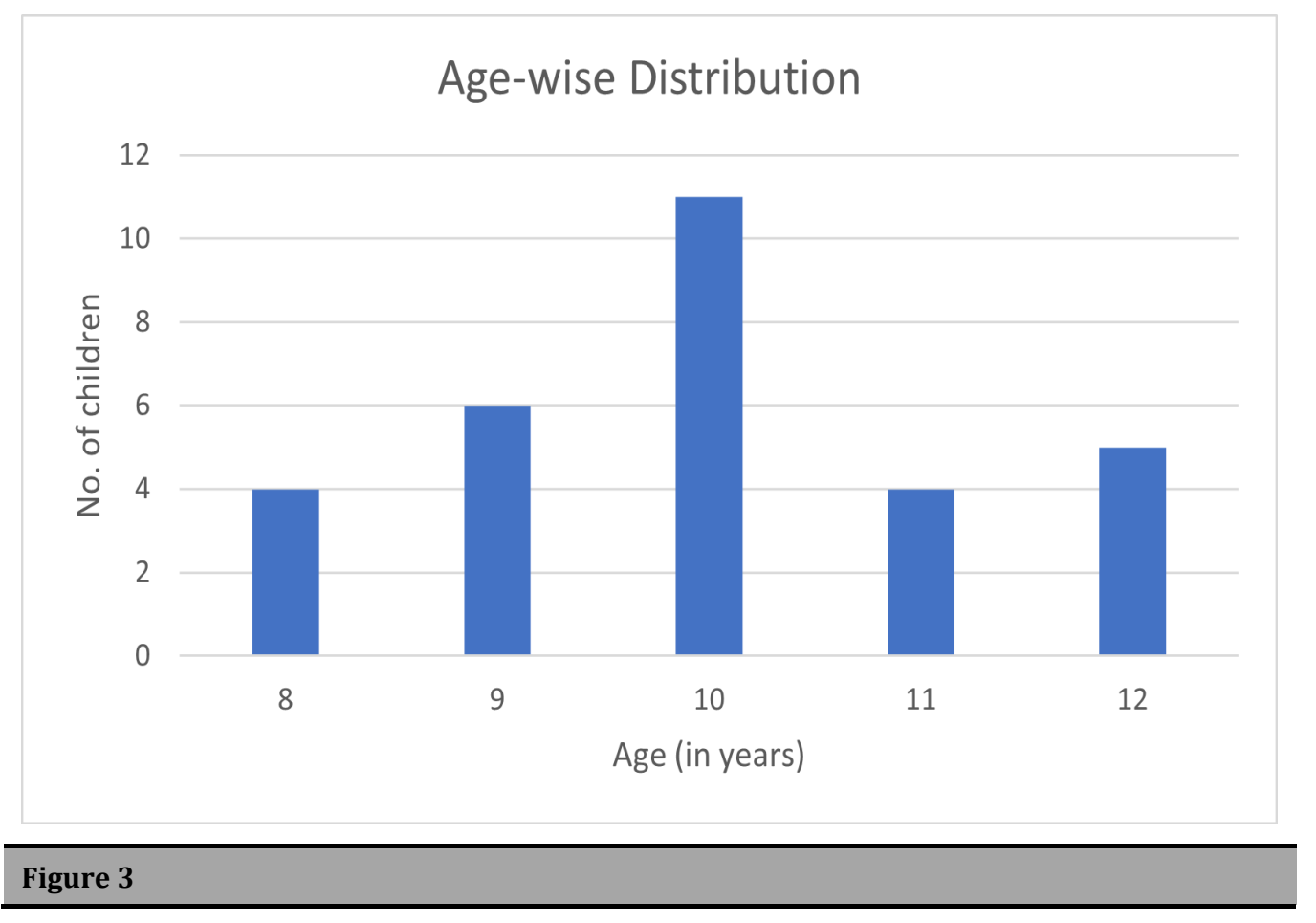

They were asked to create drawings by using pencil, black pen, or a black marker. The topic given to them for drawing was "My Favourite". They were free to draw anything which they thought as their favourite. Out of 30 children, 21 drew products in their drawings out of which 18 drawings were of the branded products or famous characters. The categorization of drawings made based on materialistic and non-materialistic values is shown in Figure 4. The further categorization of materialistic or product-based drawings into branded and non-branded product is shown in Figure 5. 

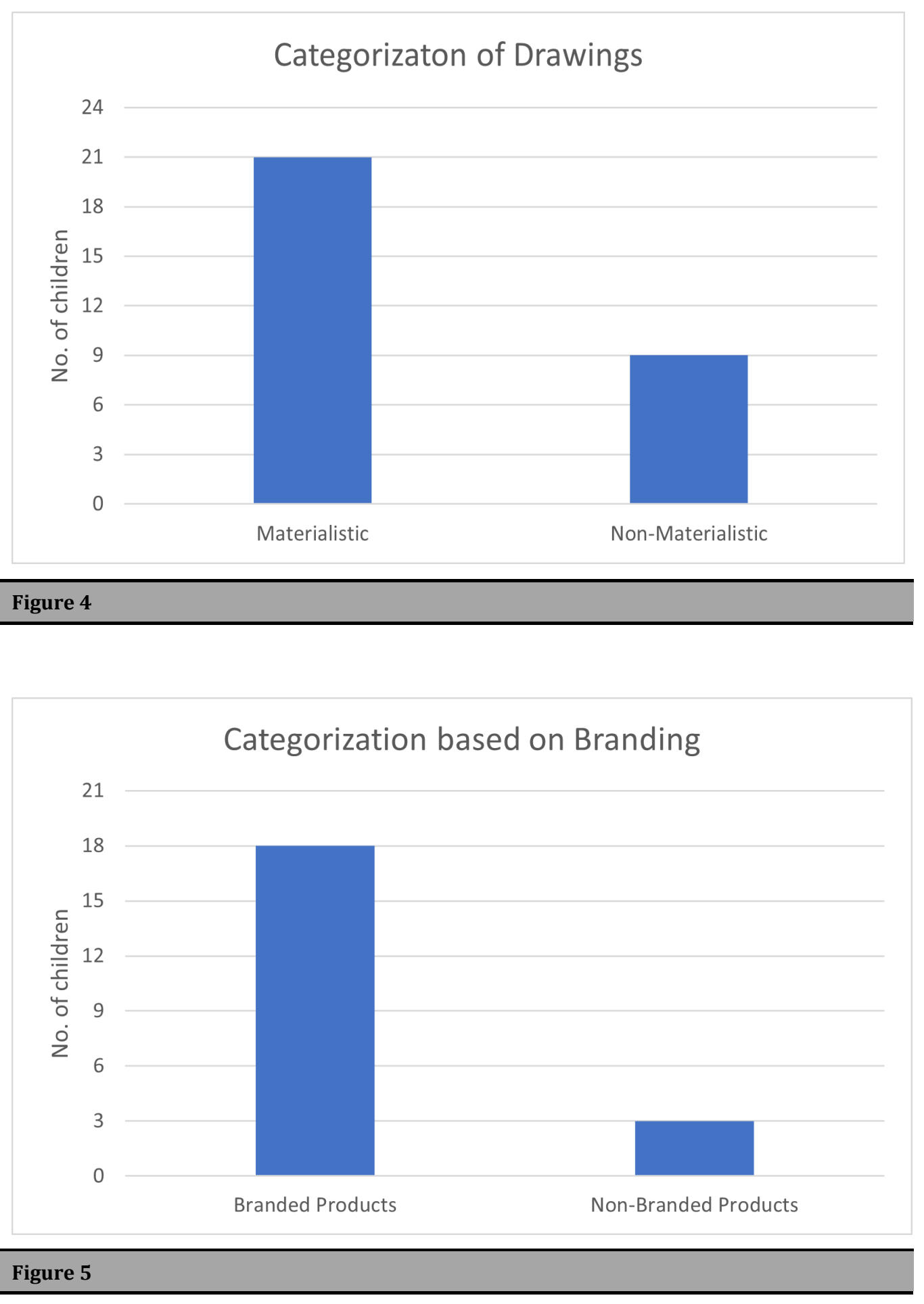

They either copied the character as it is or, they wrote the brand name on the product in their drawings. This shows a clear impression of branding and advertising on children. Apart from this, I also asked a few questions from the children regarding their drawings. Since the questions were spontaneous and based on the drawings made by the children therefore there is no specific questionnaire for this research. The questions were related to the products they drew, such as: why they drew this product/character? What do they like about it? How they come to know about it? And the answers were such: they like the product because their 
friends like it, which shows the peer influence. Whereas, others said, they like the product itself. Also, they like the advertisement of the brand. Some even said that they like the colours of the brand such as Maggi - red and yellow, contrasting colours attract them.

Increasing materialism in children is also a matter of concern. The research also shows that the advertising promotes materialistic values. In a survey, it has been found that the teenagers and tweens have become one of the most brand oriented and materialistic generation. A survey of youth conducted in 70 cities in more than 15 countries concluded that around 75\% of tweens wanted to be rich in India and in United States of America. It is highest as compared to other countries Schor (2004). In my research also, only 9 children drew their home, family, peers, or God/Goddess as their favourites. Rest of the drawings were related to products. Some of the drawings are as follows:
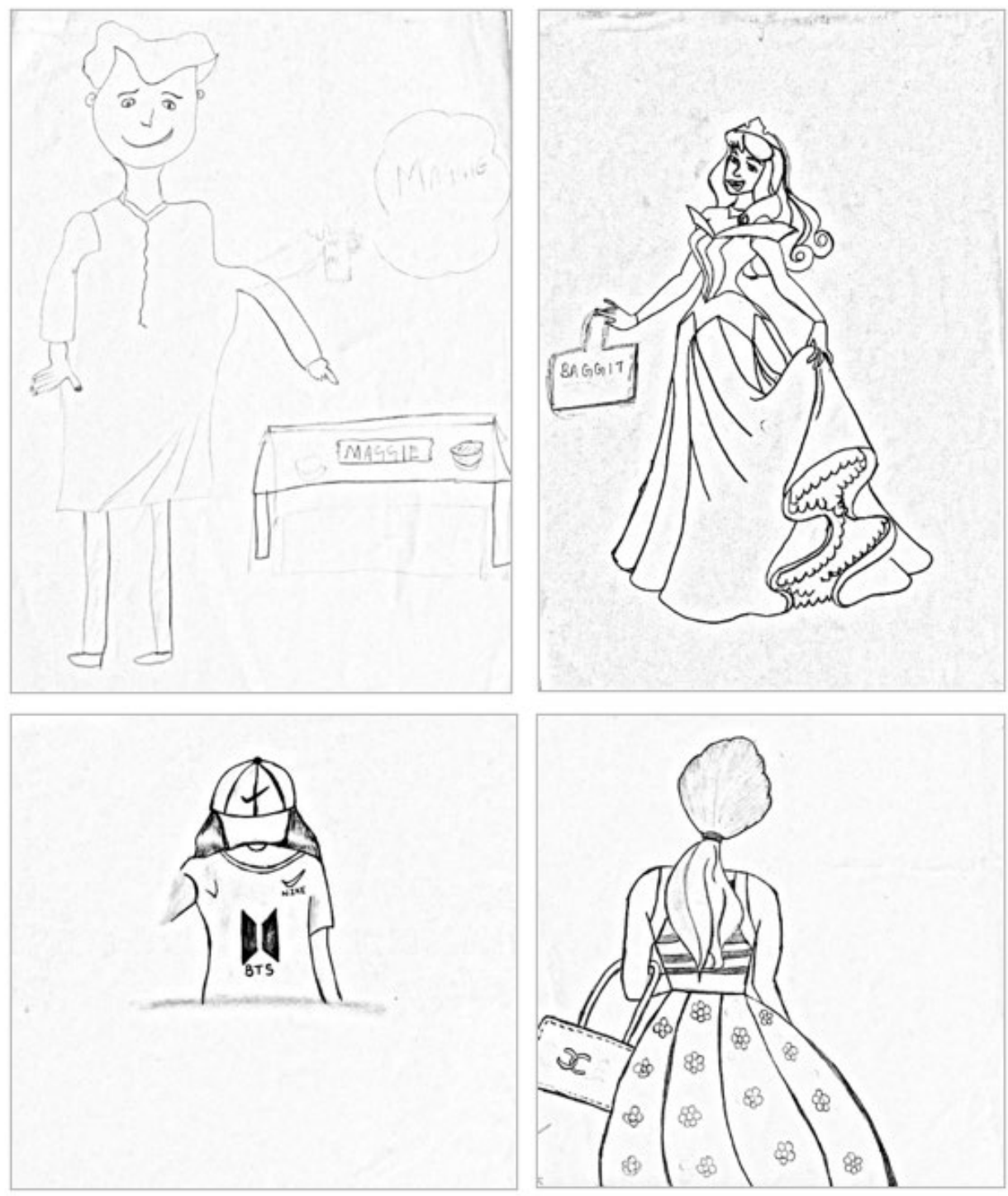

Figure 6 Some of the drawings made by children on the topic "My Favourite", in the drawings the impact of advertising, branding, or famous cartoon characters is visible. 


\section{CONCLUSION}

The result shows a clear impression of advertising and branding on children. It was visible in their drawings. Children are becoming more brand aware and brand conscious day by day due to the increasing media exposure. Apart from this, the advertisers and marketers are targeting children directly, which is a matter of concern. They use various innovative and creative methods to attract children and persuade them. Sometimes they target them to pester their parents, which may affect the parent-child relationship in a negative manner. The increasing materialism amongst children is also alarming as it may impact their emotional well-being and relations.

\section{REFRENCES}

Anning, A., \& Ring, K. (2004). Making Sense of Children's Drawings. McGraw-Hill Education (UK).

Arnheim, R. (2004). Art and Visual Perception : A Psychology of the Creative Eye. California : University of California Press.

Blades, M., Oates, C., Blumberg, F., \& Gunter, B. (Eds.). (2014). Advertising to Children : New Directions, New Media. Palgrave Macmillan. Retrieved from https://doi.org/10.1057/9781137313256.

Eynullaeva, E., \& Woodward-Smith, E. (2012, January). The Verbal and the Visual in Advertising Language : A Cross-cultural Analysis.

Golomb, C. (2004). The Child's Creation of A Pictorial World. Psychology Press.

Hurwitz, A., \& Day, M. (2007). Children and their Art : Methods for the Elementary School (Eighth ed.). Thomson Wadsworth.

Quaglia, R., Longobardi, C., Iotti, N. O., \& Prino, L. E. (2015). A New Theory On Children's Drawings : Analyzing The Role of Emotion And Movement In Graphical Development. Infant Behavior and Development, 39, 81-91. https://doi.org/10.1016/j.infbeh.2015.02.009.

Saraf, V. (2013). Impact of Celebrity Endorsement on Children through TV Advertisements. International Journal of Marketing \& Business Communication, 2(2), 53-64.

Schor, J. (2004). Born To Buy : The Commercialised Child And The New Consumer Culture. New york : Scribner.

Sharma, P., \& Gupta, P. (2015). Semiotic Analysis of Indian Television. Advertisements And Its Impact on Consumers : An Exploratory Study. ESSACHESS - Journal for Communication Studies, 71-90.

Willats, J. (2005). Making Sense of Children's Drawing. New Jersey : Lawrence Erlbaum Associates. 